\title{
Low-loss as-grown germanosilicate layers for optical waveguides
}

Feridun Ay and Atilla Aydinli ${ }^{\mathrm{a}}$

Department of Physics, Bilkent University, 06800 Ankara, Turkey

Sedat Agan

Department of Physics, Kirikkale University, 71450 Kirikkale, Turkey

(Received 13 August 2003; accepted 10 October 2003)

\begin{abstract}
We report on systematic growth and characterization of low-loss germanosilicate layers for use in optical waveguide technology. The films were deposited by plasma-enhanced chemical vapor deposition technique using silane, germane, and nitrous oxide as precursor gases. Fourier transform infrared spectroscopy was used to monitor the compositional properties of the samples. It was found that addition of germane leads to decreasing of $\mathrm{N}-\mathrm{H}-$ and $\mathrm{O}-\mathrm{H}$-related bonds. The propagation loss values of the planar waveguides were correlated with the decrease in the hydrogen-related bonds of the as-deposited waveguides and resulted in very low values, eliminating the need for high-temperature annealing as is usually done. (C) 2003 American Institute of Physics.
\end{abstract}

[DOI: $10.1063 / 1.1631753$ ]

In recent years, a lot of attention has been paid to fabrication of silicon-based dielectric materials. Among them germanosilicate films $\left[\mathrm{SiO}_{x}: \mathrm{Ge}\right.$ or $\left.\left(\mathrm{SiO}_{2}\right)_{x}:\left(\mathrm{GeO}_{2}\right)_{1-x}\right]$ attract special interest due to their excellent compatibility with single-mode fibers. ${ }^{1}$ Using germane as the core dopant and silica as the substrate, ensures nearly identical characteristics for planar waveguides with the existing fiber technology. Moreover, promising phenomena such as significant UV photosensitivity $^{2}$ and second-harmonic generation ${ }^{3}$ have already been shown in germanosilicate waveguides, providing great potential for optical applications. ${ }^{4}$

Planar germanosilicate layers are conventionally grown by rf sputtering, ${ }^{3}$ sol-gel methods, ${ }^{1}$ powder melting, ${ }^{5,6}$ or plasma-enhanced chemical vapor deposition (PECVD) techniques. ${ }^{4}$ As-deposited $\mathrm{SiO}_{x}$ : $\mathrm{Ge}$ optical waveguides grown with these methods all share the shortcomings of having relatively large propagation losses at wavelengths of $632.8 \mathrm{~nm}$ and $1.55 \mu \mathrm{m}$. In particular, loss at $\lambda=1.55 \mu \mathrm{m}$ is known to be caused mainly by $\mathrm{N}-\mathrm{H}$ and $\mathrm{O}-\mathrm{H}$ bonds incorporated into the film matrix, while loss at $632.8 \mathrm{~nm}$ is due mainly to scattering mechanisms. ${ }^{7}$ Although there is no systematic study of propagation loss in germanosilicate planar waveguides, the reported values range between 3.5 and 10 $\mathrm{dB} / \mathrm{cm}^{1,2}$ at $\lambda=632.8 \mathrm{~nm}$ and are larger than $2 \mathrm{~dB} / \mathrm{cm}$ at $\lambda=1.55 \mu \mathrm{m} .{ }^{8}$ To reduce the loss, it is common practice to anneal the as-grown layers at temperatures as high as $1100{ }^{\circ} \mathrm{C}$ for prolonged times. ${ }^{1,9}$ Recently, Zhang et al. ${ }^{9}$ reported CVD-grown germanosilicate planar waveguides with propagation losses of about 2 and $1 \mathrm{~dB} / \mathrm{cm}$ at wavelengths of 632.8 and $1550 \mathrm{~nm}$, respectively. However, due to low index contrast, almost half of the mode power in those waveguides propagate in the cladding material, the effect of which is not taken into account in the reported loss values.

In this study, we report on systematic characterization of as-grown germanosilicate waveguides. The layers were grown by standard PECVD technique by using silane, ger-

\footnotetext{
${ }^{a}$ Electronic mail: aydinli@fen.bilkent.edu.tr;

URL: http://www.fen.bilkent.edu.tr/ iogroup/
}

mane, and nitrous oxide as precursor gases. It was found that increasing the germane flow rate leads to decreasing of the hydrogen related bonds and thus decreasing of the propagation loss to the lowest values reported so far.

A series of germanosilicate films was grown by using parallel-plate-type Plasmalab 8510C PECVD reactor. The layers were grown on high-resistivity silicon wafers with both sides polished at $350{ }^{\circ} \mathrm{C}$, in a pressure of 1 Torr and $\mathrm{rf}$ power of $10 \mathrm{~W}$ at a frequency of $13.56 \mathrm{MHz}$, applied to plates with a diameter of $24 \mathrm{~cm}$. Silane $\left(2 \% \mathrm{SiH}_{4} / \mathrm{N}_{2}\right)$ and nitrous oxide $\left(\mathrm{N}_{2} \mathrm{O}\right)$ gas flow rates were kept constant at 180 and $225 \mathrm{sccm}$, while that of germane $\left(2 \% \mathrm{GeH}_{4} / \mathrm{He}\right)$ has been varied between 0 and $70 \mathrm{sccm}$. The refractive index of the films was measured by a prism-coupling technique ${ }^{10}$ at $\lambda=632.8$ and $1550 \mathrm{~nm}$, and the film thicknesses were determined by the same method and by stylus profilometry. As the $\mathrm{GeH}_{4}$ flow rate was increased from 5 to $50 \mathrm{sccm}$, the refractive index of the layers varied between 1.4683 and 1.5189 $( \pm 0.0002)$ for TE-polarized light, and between 1.4681 and 1.5191 for TM-polarized light at $\lambda=632.8 \mathrm{~nm}$. At $\lambda=1550$ $\mathrm{nm}$, the corresponding refractive indices were measured to vary between 1.4530 and 1.5033 , and between 1.4527 and 1.5032 for TE and TM polarizations, respectively. The growth rate of the films increased gradually from 370 to 440 $\AA /$ min with increasing $\mathrm{GeH}_{4}$ flow rate.

The compositional analysis of the germanosilicate films was done by making use of Bomem H\&B Series Fourier transform infrared (FTIR) spectrometer. The spectra were obtained in the 5500 to $250 \mathrm{~cm}^{-1}$ range with $8 \mathrm{~cm}^{-1}$ resolution. The thicknesses of the $\mathrm{SiO}_{x}$ : Ge layers deposited for FTIR characterization were between 1.5 and $2.5 \mu \mathrm{m}$. Eight samples, s0-s7, with corresponding $\mathrm{GeH}_{4}$ flow rates of 0 (i.e., $\mathrm{SiO}_{x}$ ), 5, 10, 20, 30, 50, 60, and $70 \mathrm{sccm}$, were used for compositional characterization. Normalized absorbance spectra of the samples in 250 to $1500 \mathrm{~cm}^{-1}$ range are shown in Fig. 1. All the samples show a dominant absorption feature around $1050 \mathrm{~cm}^{-1}$, which can be resolved into $\mathrm{Si}-\mathrm{O}$ symmetric and asymmetric stretching and $\mathrm{Ge}-\mathrm{O}$ stretching 


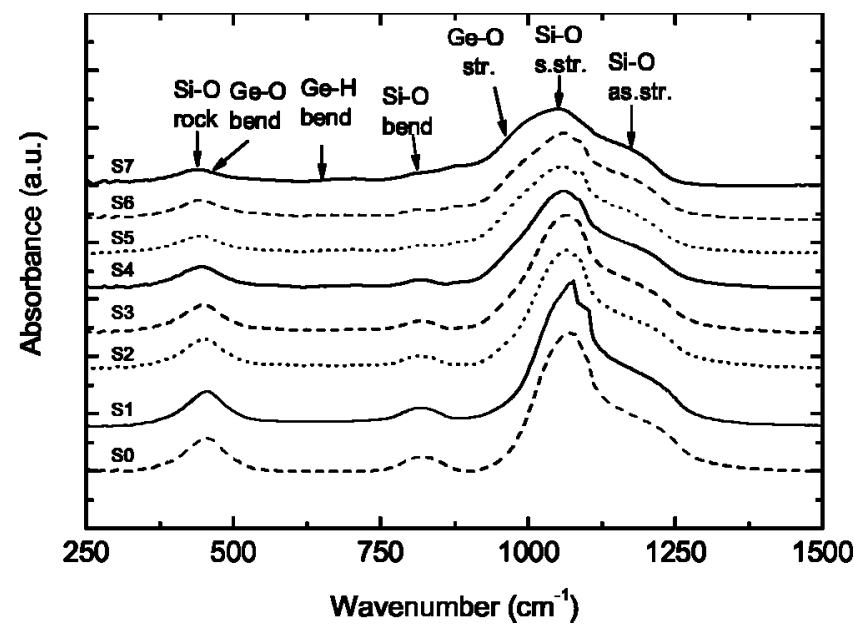

FIG. 1. Infrared absorption spectra of germanosilicate samples at the 250 to $1550 \mathrm{~cm}^{-1}$ range with the following $\mathrm{GeH}_{4}$ flow rates; $\mathrm{s} 0,0 ; \mathrm{s} 1,5 ; \mathrm{s} 2,10 ; \mathrm{s} 3$, 20 ; s4, 30; s5, 50; s6, 60; and s7, $70 \mathrm{sccm}$.

vibrations $^{11,12}$ at frequencies of about 1065, 1150, and $980 \mathrm{~cm}^{-1}$, respectively. Si-O rocking and bending vibrations were identified at $\sim 450$ and $\sim 820 \mathrm{~cm}^{-1}$, while $\mathrm{Ge}-\mathrm{O}$ and $\mathrm{Ge}-\mathrm{H}$ bending vibrations were observed at $\sim 420$ and $\sim 650 \mathrm{~cm}^{-1}$, respectively. Analysis of the oxygen bond concentration was performed by integrating over the relevant bands. The bands were decomposed using nonlinear curve fitting, assuming that the peaks are in the form of symmetric Gaussians. The results of this analysis are plotted in Fig. 2. The normalized integrated absorption $\left.\left[\int_{\text {band }} \alpha(\omega) d \omega\right)\right]$ of the $\mathrm{Si}-\mathrm{O}$ bonds exhibited a gradual decrease, while that of $\mathrm{Ge}-\mathrm{O}$ bonds showed a steady increase as a function of germane flow rate. Both reached saturation at a $\mathrm{GeH}_{4}$ flow rate of about $50 \mathrm{sccm}$. Assuming that the infrared absorption cross section for the bonds of interest are similar, it can be stated that $\mathrm{Si}$ and $\mathrm{Ge}$ are incorporated into the film matrix at nearly equal concentrations for $\mathrm{GeH}_{4}$ flow rate of $50 \mathrm{sccm}$ and larger.

An interesting outcome of the FTIR analysis is that the observed amount of both $\mathrm{N}-\mathrm{H}$ and $\mathrm{O}-\mathrm{H}$ bonds decreased with increasing $\mathrm{GeH}_{4}$ flow rate (see Fig. 3). The $\mathrm{N}-\mathrm{H}$ stretching vibrations were observed at $\sim 3380 \mathrm{~cm}^{-1}$, $\mathrm{GeO}-\mathrm{H}$ stretching vibrations at $\sim 3470$ and $\sim 3515 \mathrm{~cm}^{-1}$,

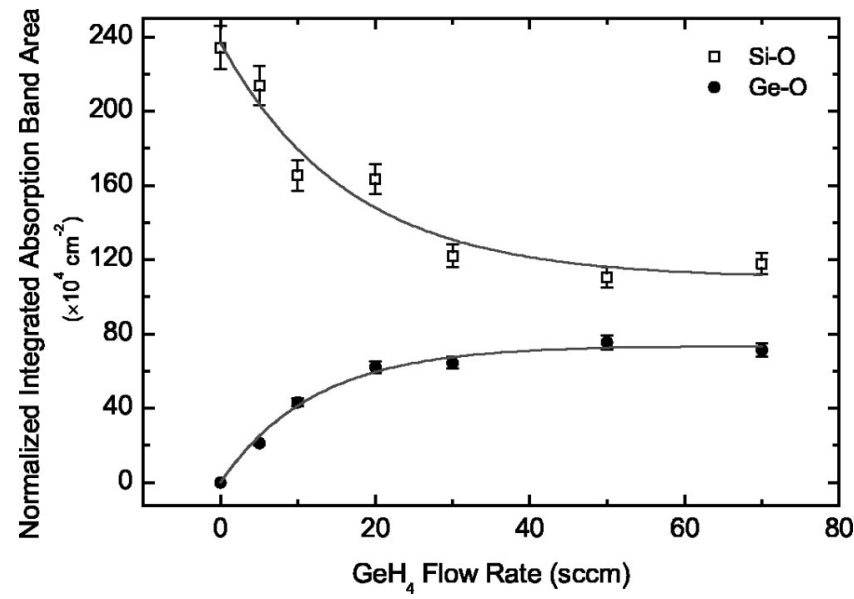

FIG. 2. Variation of normalized absorption band area for Si-O- and Ge-O-

related bonds with increasing $\mathrm{GeH}_{4}$ flow rate.
Downloaded 17 May 2011 to 139.179.14.104. Redistribution subject to AIP license or copyright; see http://apl.aip.org/about/rights_and_permissions

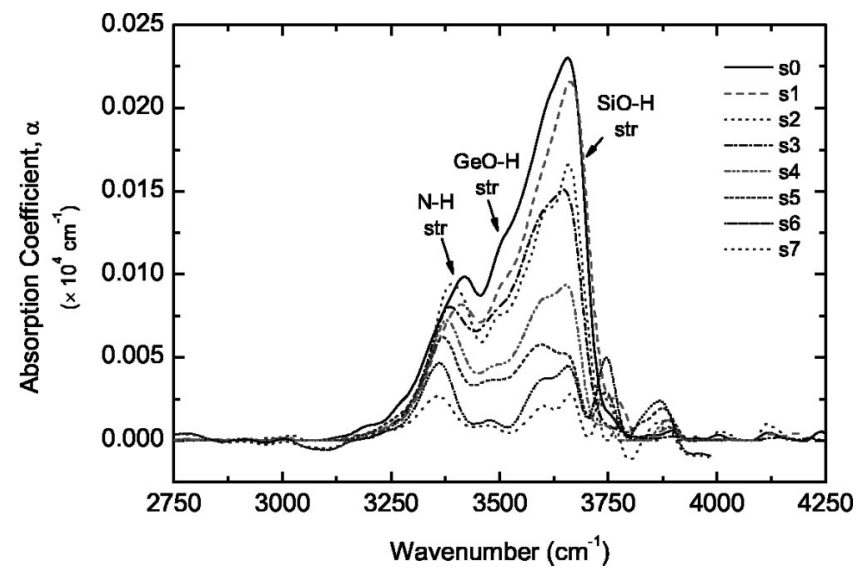

FIG. 3. FTIR absorption coefficient $\alpha$ vs wavenumber for the germanosilicate samples in the $\mathrm{N}-\mathrm{H}$ and $\mathrm{O}-\mathrm{H}$ absorption band region.

and finally $\mathrm{SiO}-\mathrm{H}$ stretching vibrations at $\sim 3600$ and $\sim 3665 \mathrm{~cm}^{-1} .{ }^{6}$ As the $\mathrm{GeH}_{4}$ flow rate in the grown samples increased, the $\mathrm{N}-\mathrm{H}$ stretching vibrational frequency shifted about $30 \mathrm{~cm}^{-1}$ towards lower frequencies, while that of $\mathrm{GeO}-\mathrm{H}$ and $\mathrm{SiO}-\mathrm{H}$ remained constant. The $\mathrm{N}-\mathrm{H}$ and $\mathrm{O}-\mathrm{H}$ bond concentrations were calculated for all the grown layers by using the method of Lanford and Rand. ${ }^{13}$ For N-H bonds, the absorption cross section value of $\sigma_{\mathrm{N}-\mathrm{H}}=5.3$ $\times 10^{-18} \mathrm{~cm}^{2}$ was used throughout the calculations. The corresponding value for $\mathrm{O}-\mathrm{H}$ bonds, was $\sigma_{\mathrm{O}-\mathrm{H}}=1.5$ $\times 10^{-21} \mathrm{~cm}^{2}$, obtained by Rostaing et al. ${ }^{14}$ In spite of the relatively large uncertainty for the $\mathrm{O}-\mathrm{H}$ bond absorption cross section, we believe that the results obtained can be safely used in the comparison of $\mathrm{O}-\mathrm{H}$ bond concentrations of the samples. The results of the calculations are plotted in Fig. 4. As seen from the figure, the $\mathrm{N}-\mathrm{H}$ bond concentration has decreased from $0.43 \times 10^{22} \mathrm{~cm}^{-3}$ below our detection limit of $0.06 \times 10^{22} \mathrm{~cm}^{-3}$, by a factor of 7 as the $\mathrm{GeH}_{4}$ flow rate increased from 0 (silicon oxide) to $70 \mathrm{sccm}$. As for the $\mathrm{O}-\mathrm{H}$ bonds, their concentration showed a sharp decrease as well, from about $2.27 \times 10^{22} \mathrm{~cm}^{-3}$ down to 0.23 $\times 10^{22} \mathrm{~cm}^{-3}$, by a factor of 10 in the same germane flow range. The observed decrease of these bonds has an important impact on propagation losses at $\lambda=1.55 \mu \mathrm{m}$ of the waveguides grown using germanosilicate films.

The propagation losses of the waveguides were measured by using a prism coupling technique. The waveguides

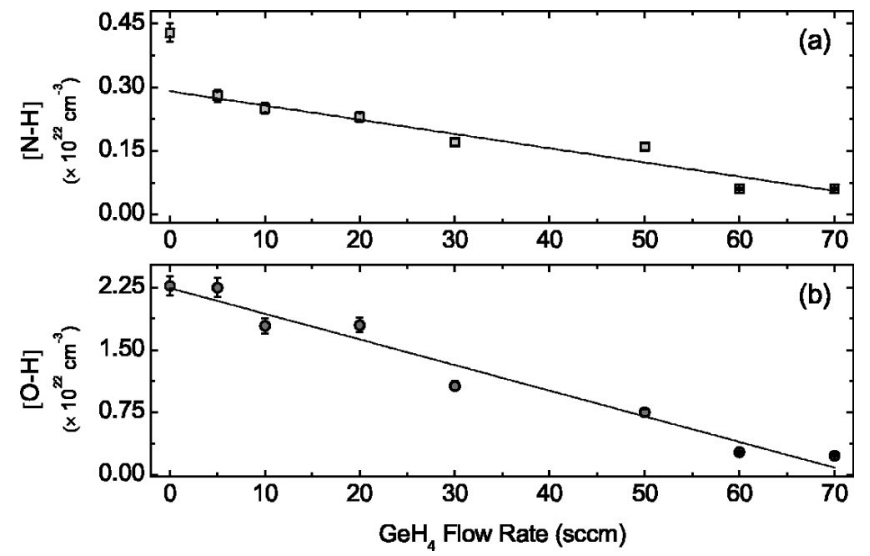

FIG. 4. Variation of calculated $\mathrm{N}-\mathrm{H}$ (a) and $\mathrm{O}-\mathrm{H}$ (b) bond concentrations for germanosilicate samples with increasing $\mathrm{GeH}_{4}$ flow rate. 
TABLE I. Propagation loss variation with $\mathrm{GeH}_{4}$ flow rate for three representative germanosilicate waveguides at $\lambda=1.55 \mu \mathrm{m}$.

\begin{tabular}{cccc}
\hline \hline & \multicolumn{2}{c}{$\begin{array}{c}\mathrm{GeH}_{4} \text { flow } \\
\text { rate } \\
\begin{array}{c}\text { Sample } \\
\text { no. }\end{array}\end{array}$} & \multicolumn{2}{c}{$\begin{array}{c}\text { Propagation loss } \\
(\mathrm{dB} / \mathrm{cm})\end{array}$} \\
\hline S1 & 5 & $0.32 \pm 0.03$ & $\mathrm{TM}$ \\
S2 & 10 & $0.20 \pm 0.05$ & $0.22 \pm 0.04$ \\
S5 & 50 & $0.14 \pm 0.06$ & $0.18 \pm 0.02$ \\
\hline \hline
\end{tabular}

were grown on oxidized silicon wafers with $\mathrm{SiO}_{2}$ thickness of $9.8 \mu \mathrm{m}$. Core layer thicknesses were varied between 4 and $6 \mu \mathrm{m}$, by using the same parameters as the samples used in FTIR characterization. At $\lambda=1.55 \mu \mathrm{m}$, the moving-prism method was used, in which light was coupled into the waveguide at different lengths and the output power was monitored at the end of the slab waveguide. At $\lambda=632.8 \mathrm{~nm}$, the method of Ramponi et al. ${ }^{15}$ was employed, in which a single prism and measurement of reflected and transmitted light are used to determine the propagation losses. In order to compare the propagation losses of our films, care must be taken to take the confinement factor of each waveguide into account. Depending on the index contrast and thicknesses of the layers, some fraction of the total time averaged power travels in the core layer of the waveguide and the remaining power propagates in the cladding layer.

This issue can be overcome by normalizing the measured loss to identical predetermined fraction of the total power propagating in the core layer. With this approach, loss values of germanosilicate planar waveguides with different index contrast and thicknesses can be compared to each other. In this work, the fraction of power traveling in the guiding layer was chosen to be same as in the waveguides studied by Zhang et al. ${ }^{9}$ The results of the loss analysis for three representative waveguides grown with different germane flow rates are summarized in Table I. For purpose of completeness, raw values of the measured loss rates for TE polarization at $\lambda=1.55 \mu \mathrm{m}$ are $0.55 \pm 0.06,0.37 \pm 0.10$, and $0.27 \pm 0.11 \mathrm{~dB} / \mathrm{cm}$ for the samples $\mathrm{s} 1$, s2, and $\mathrm{s} 5$, respectively. The measured propagation loss values at $\lambda=632.8 \mathrm{~nm}$ for the same samples at TE polarization are $0.20 \pm 0.02,0.34$ \pm 0.17 , and $6.46 \pm 0.04 \mathrm{~dB} / \mathrm{cm}$, respectively. The observed trend of propagation loss increase at $\lambda=632.8 \mathrm{~nm}$ is similar to the results available in the literature. Specifically, as the Ge content of the layers increases, the propagation loss in- creases as well, due mainly to scattering mechanisms. ${ }^{2,16}$ As for the propagation loss values at $\lambda=1.55 \mu \mathrm{m}$, they are in agreement with our expectations based on FTIR analysis. The normalized propagation loss rates showed a decrease by a factor of 2, while approaching our measurement limit, and following the decreasing $\mathrm{N}-\mathrm{H}$ bond concentration.

In summary, we have grown germanosilicate layers using the PECVD technique. Compositional analysis using FTIR spectroscopy showed that the amount of $\mathrm{N}-\mathrm{H}$ and $\mathrm{O}-\mathrm{H}$ related bonds exhibited a drastic decrease upon increasing $\mathrm{GeH}_{4}$ flow rate. Planar waveguides fabricated with germanosilicate core layers showed the lowest propagation loss values reported so far both for as deposited and annealed layers at $\lambda=1.55 \mu \mathrm{m},{ }^{9}$ eliminating the need for costly and cumbersome annealing process.

The authors gratefully acknowledge the support of The Scientific and Technical Research Council of Turkey (TUBITAK, Project No: 199E006) and Bilkent University Research Fund (Code: Phys-03-02).

${ }^{1}$ D. G. Chen, B. G. Potter, and J. H. Simmons, J. Non-Cryst. Solids 178, 135 (1994).

${ }^{2}$ K. S. Potter, B. G. Potter, D. C. Mclntyre, and P. D. Gandon, Appl. Phys. Lett. 68, 2011 (1996).

${ }^{3}$ O. Sugihara, M. Nakanishi, H. Fujimura, C. Egami, and N. Okamoto, J. Opt. Soc. Am. B 15, 421 (1998).

${ }^{4}$ R. A. Jarvis, J. D. Love, A. Durandet, G. D. Conway, and R. W. Boswell, Electron. Lett. 32, 550 (1996).

${ }^{5}$ Q. Zeng, J. F. Stebbins, A. D. Heaney, and T. Erdogan, J. Non-Cryst. Solids 258, 78 (1999).

${ }^{6}$ V. G. Plotnichenko, V. O. Sokolov, and E. M. Dianov, J. Non-Cryst. Solids 278, 85 (2000).

${ }^{7}$ B. S. Sahu, O. P. Agnihotri, S. C. Jain, R. Mertens, and I. Kato, Semicond. Sci. Technol. 15, L11 (2000).

${ }^{8}$ D. Moss, J. Canning, and M. Bazylenko, Conference on Lasers and Electro-Optics Technical Digest (Optical Society of America, Washington DC, 1998), p. 245.

${ }^{9}$ Q. Y. Zhang, K. Pita, C. K. F. Ho, N. Q. Ngo, L. P. Zuo, and S. Takahashi, Chem. Phys. Lett. 368, 183 (2003).

${ }^{10}$ P. K. Tien, Appl. Opt. 10, 2395 (1971).

${ }^{11}$ Y. P. Chou and S. C. Lee, J. Appl. Phys. 83, 4111 (1998).

${ }^{12}$ G. Lucovsky, S. S. Chao, J. Yang, J. E. Tyler, R. C. Ross, and W. Czubatyj, Phys. Rev. B 31, 2190 (1985).

${ }^{13}$ W. A. Lanford and M. J. Rand, J. Appl. Phys. 49, 2473 (1978).

${ }^{14}$ J. C. Rostaing, Y. Cross, S. C. Gujrathi, and S. Poulain, J. Non-Cryst. Solids 97-98, 1051 (1987).

${ }^{15}$ R. Ramponi, R. Osellame, and M. Marangoni, Rev. Sci. Instrum. 73, 1117 (2002).

${ }^{16}$ T. Kominato, Y. Ohmori, N. Takato, H. Okazaki, and M. Yasu, J. Lightwave Technol. 10, 1781 (1992). 